\title{
Analysis of Fatigue Crack Propagation in Steel I-Beams with Welded Transverse Stiffeners Subjected to In-Plane Loadings
}

\author{
Wanchalerm Triamlumlerd $^{\mathrm{a}}$ and Akhrawat Lenwari ${ }^{\mathrm{b}, *}$ \\ Department of Civil Engineering, Faculty of Engineering, Chulalongkorn University, Phayathai Rd., \\ Pathumwan, Bangkok 10330, Thailand \\ E-mail: at.wanchalerm@hotmail.com, bakhrawat.1@chula.ac.th (Corresponding author)
}

\begin{abstract}
For bridge structures, the fatigue crack propagation represents the mechanical damage that shortens the service life of the structures. Most fatigue cracks initiate at the welded details due to geometric discontinuities, residual stresses, and initial weld defects. The welded transverse stiffeners have been widely used to increase shear strength of the steel girders. Under cyclic in-plane loadings, however, the fatigue crack initiates at the end of the stiffener, i.e., in the web gap, and propagates into the girder web. The objectives of this study are to (1) numerically simulate the fatigue crack propagation in steel I-girders with welded transverse stiffeners and (2) study the effects of initial crack size, fillet weld size, stiffener dimension, and web-gap length on the fatigue crack propagation. The FRANC3D software was used to perform the analysis of stress intensity factor, crack propagation, and fatigue life. The numerical results showed that the fatigue life increases as the web-gap length increases, while it decreases as initial crack size and thickness of the transverse stiffener increase. Also, the stress intensity factors of the steel I-beams that include the fillet weld in the finite element models are slightly lower than ones modelled without fillet weld.
\end{abstract}

Keywords: Fatigue crack propagation, steel bridges, welded transverse stiffeners, in-plane loadings, FRANC3D.

ENGINEERING JOURNAL Volume 21 Issue 4

Received 16 January 2017

Accepted 11 February 2017

Published 31 July 2017

Online at http://www.engj.org/

DOI:10.4186/ej.2017.21.4.307 


\section{Introduction}

Most fatigue cracks in steel bridges occur at welded details where stress concentration due to geometric discontinuities, high tensile residual stresses, and weld defects are present. Transverse stiffeners welded to the web of steel girder are commonly used to increase the static shear strength of a steel girder [1]. Under cyclic in-plane loadings, however, fatigue crack typically initiates at the weld toe at the bottom end of transverse stiffeners. Figure 1 shows a typical fatigue crack propagation in steel I-beams with welded transverse stiffeners [2]. It consists of three stages or phases. The crack first develops as a surface crack. Phase I involves the propagation of the surface or part-through crack in the web. One or more semielliptical cracks initiate at one or more points along the toe of the stiffener-to-web weld. Phase II involves the propagation of a two-tip through-thickness crack in the web after the surface crack penetrates the web plate. The through crack in the web propagates in a direction perpendicular to the principal tensile stress upward into the web and downward toward the web-to-flange junction. Under pure bending, the plane of crack propagation remains perpendicular to the longitudinal axis of the girder. Phase III involves the propagation of a three-tip crack after the two-tip web crack reaches the extreme fiber of the tension flange. The three-tip crack propagates across the flange and extends farther up into the web until the failure by either fracture or yielding of the tension flange at the net section. Approximately 80,16, and 4 percent of the total number of cycles to failure were consumed in Phase I, II, and III, respectively [1]. According to the AASHTO design specification [3], the fatigue strength of welded transvers stiffeners is classified into Category C'. The specification also recommends the gap between the bottom end of the transverse stiffeners and the tension flange, so-called "web gap", with a distance from four to six times the web thickness.

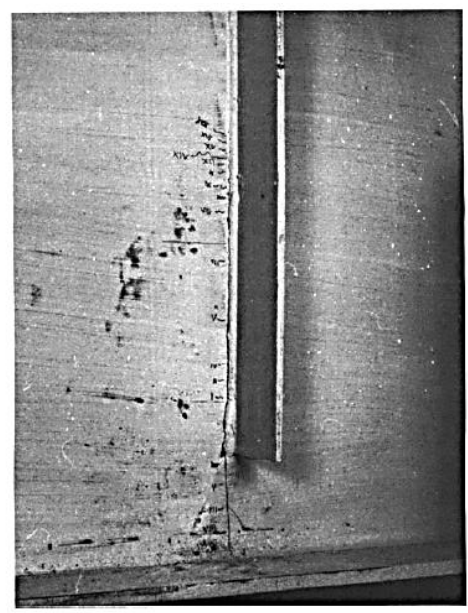

Fig. 1. Typical fatigue crack propagation in steel I-beams with welded transverse stiffeners [2].

There have been previous research works on the numerical simulation of fatigue crack propagation for some practical problems [4-8]. Kotsikos and Grasso [9] used the FRANC3D software to simulate the fatigue crack propagation at the foot region of a rail subjected to bending. Aygül et al. [10] studied the behavior of distortion-induced fatigue cracks in welded details in an existing bridge by performing crack propagation analysis based on linear elastic fracture mechanics (LEFM). The real load history of the bridge was obtained from strain measurements. The FRANC3D was used to calculate the new crack front and remesh the local model for the extended crack. Zong et al. [11] reported that the numerical simulation using FRANC3D and ABAQUS can precisely predict the fatigue life of compact tension specimens, which demonstrates that simulation method is appropriate for fatigue assessment practice of whole steel bridges based on LEFM. Abilities of the FRANC3D include the insertion of the initial crack configurations, static crack analysis for calculation of stress intensity factor $(\mathrm{K})$, and crack growth analysis. The FRANC3D can perform re-meshing automatically.

In this study, the FRAND3D version 6 [12] was used to simulate the fatigue crack propagation in steel I-beams with welded transverse stiffeners subjected to constant amplitude in-plane loadings. The ANSYS software was concurrently used to draw solid work, define supports and loadings, and be the solver for the 
FRANC3D. The main objectives are to study the effects of initial crack size, fillet weld size, stiffener dimension and web-gap length on the fatigue crack propagation. Three benchmark problems were chosen to illustrate the application of the FRAND3D for this purpose. The first problem was a semi-circular surface crack a plate under tension and bending [13]. The second problem was a two-tip through-thickness web crack in an I-beam under bending [14]. The third problem was a crack in a fillet in a structural member under mixed-mode condition [15]. After the benchmark problems were described, the analysis of fatigue crack propagation in steel I-beams with welded transverse stiffeners subjected to cyclic in-plane loadings was performed.

\section{Benchmark Problems}

\subsection{A Semi-Circular Surface Crack in a Plate under Tension and Bending}

Figure 2 shows a surface semi-elliptical crack in a plate under tension and bending in a study by Newman and Raju [13] for which the stress intensity factor values for different aspect ratios $(\mathrm{a} / \mathrm{c})$ of crack shape were given. Figure 3 shows a semi-circular shape $(\mathrm{a} / \mathrm{c}=1)$ chosen this study. Both $\mathrm{c} / \mathrm{b}$ and $\mathrm{c} / \mathrm{h}$ ratios were 0.2 .

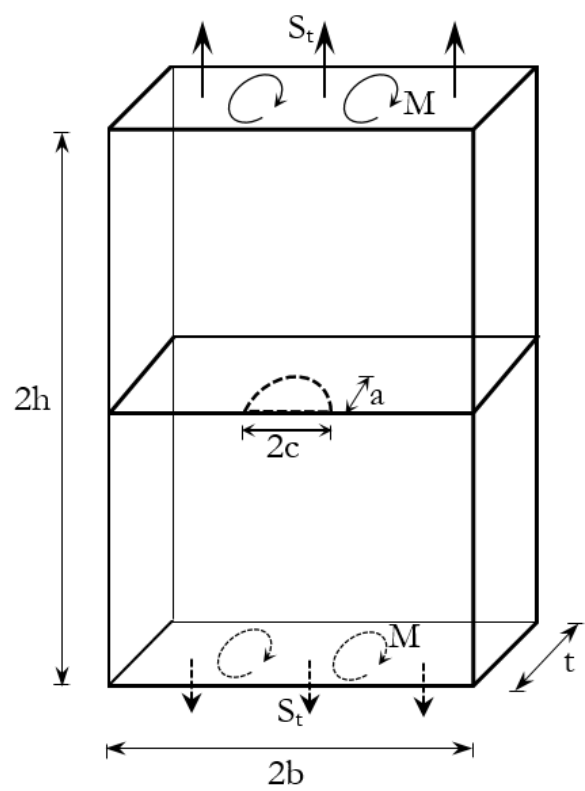

Fig. 2. A surface crack in a plate under tension and bending (adapted from [13]).
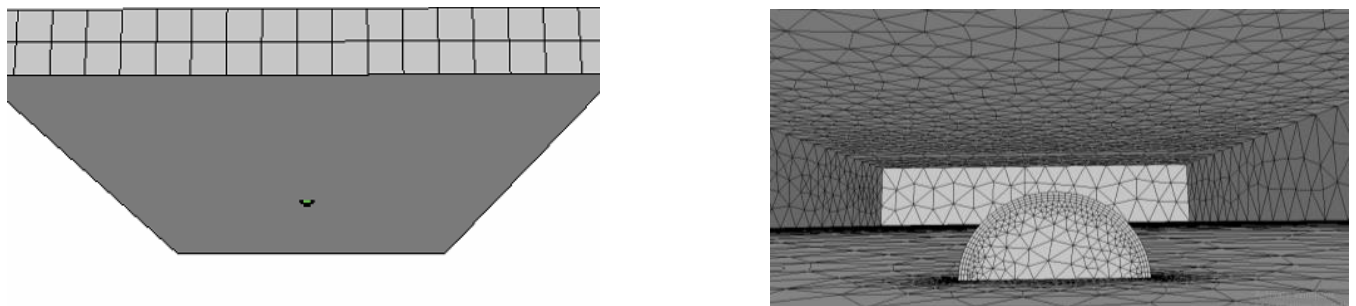

Fig. 3. An initial semi-circular crack at the surface of steel plate in FRANC3D.

Figures 4 and 5 show the finite element model, loadings, and boundary conditions for a plate subjected to tension and bending, respectively. Under tension, the thickness ( $\mathrm{t})$, width (2b), and height (2h) of the plate were 2, 30, and $50 \mathrm{~mm}$, respectively. The remote applied tensile stress was $1 \mathrm{MPa}$. The a/t ratios were $0.2,0.4,0.6$, and $0.8(\mathrm{a}=0.4,0.8,1.2$, and $1.6 \mathrm{~mm}$, respectively). Under bending, the thickness $(\mathrm{t})$, width (2b), and height (2h) of the plate were 9.5, 80, and 140, respectively. The applied bending stress was $1 \mathrm{MPa}$. The same $\mathrm{a} / \mathrm{t}$ ratios of $0.2,0.4,0.6$, and 0.8 were chosen $(\mathrm{a}=1.9,3.8,5.7$, and $7.6 \mathrm{~mm}$, respectively). 

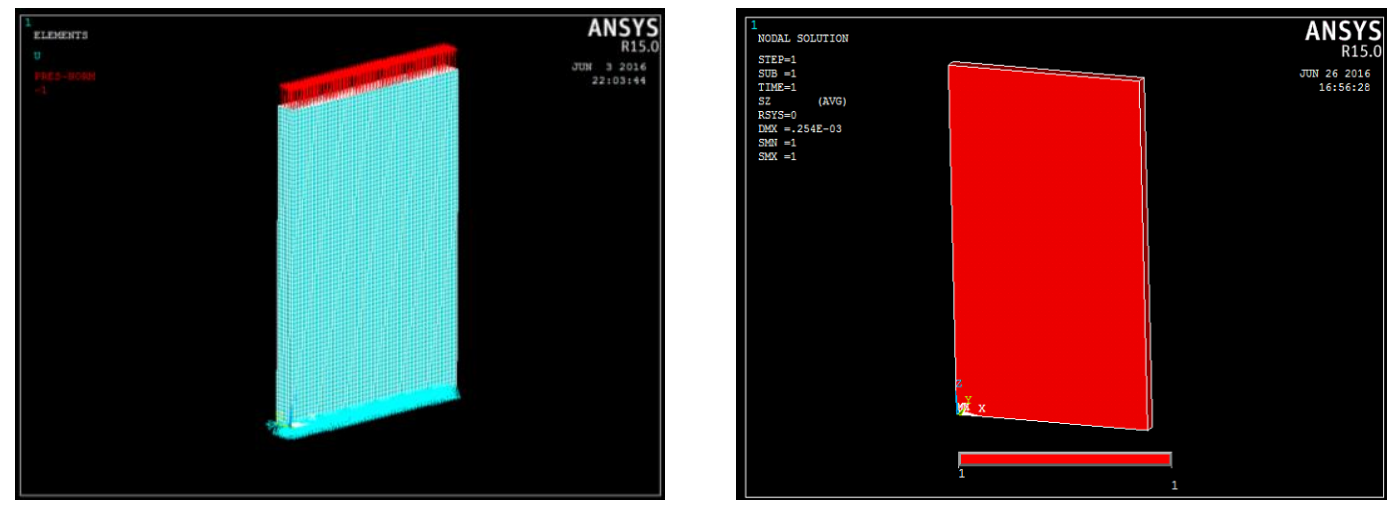

Fig. 4. A finite element model of steel plate under tension.
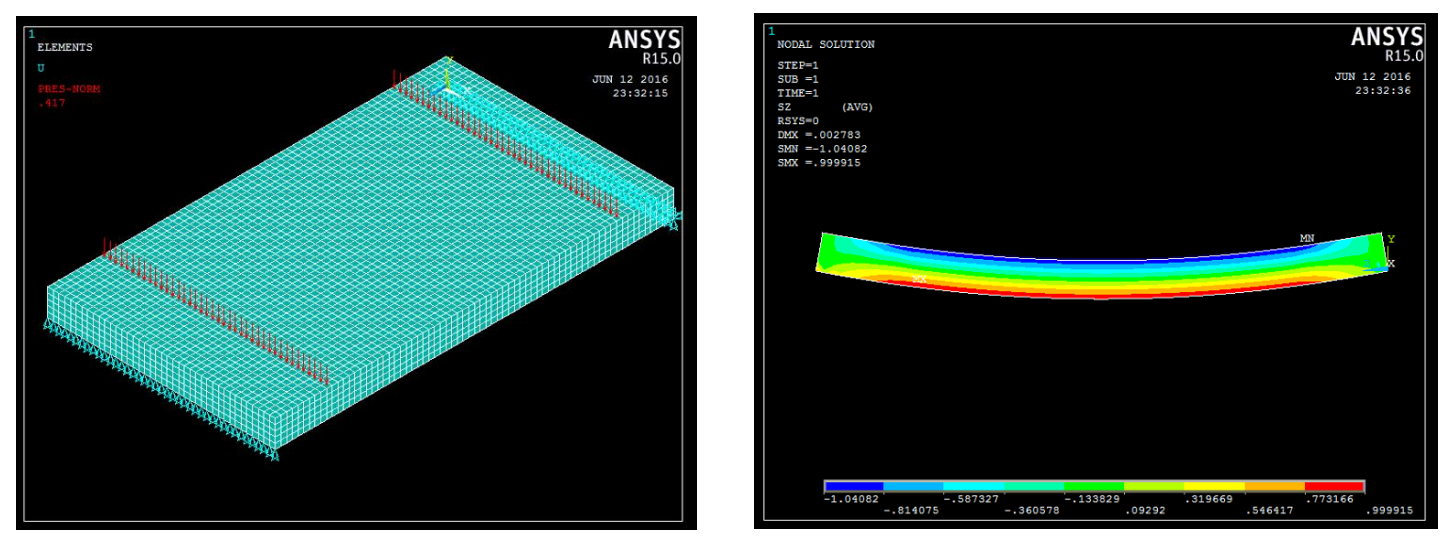

Fig. 5. A finite element model of steel plate under bending.

To compare the stress intensity factor values obtained from the FRANC3D with those from Newman and Raju [13] and Liao and Atluri [16], the stress intensity factors were normalized as follows,

$$
\text { Normalized } K=\frac{K}{S \sqrt{\pi \frac{a}{Q}}}
$$

where $S$ is the tension or bending stress and the shape factor $(Q)$ is approximated by [13]

$$
Q=1+1.464\left(\frac{a}{c}\right)^{1.65}
$$

Figures 6 and 7 compare the normalized stress intensity factors along the crack front of the semi-circular crack under tension and bending, respectively. Good agreements were observed between the FRANC3D results and Newman and Raju [13] for all a/t values, except for the a/t value of 0.2 under bending where fair agreement was noticed. Consequently, the FRANC3D can be used to calculate the stress intensity factor for a surface crack under tension or bending. 


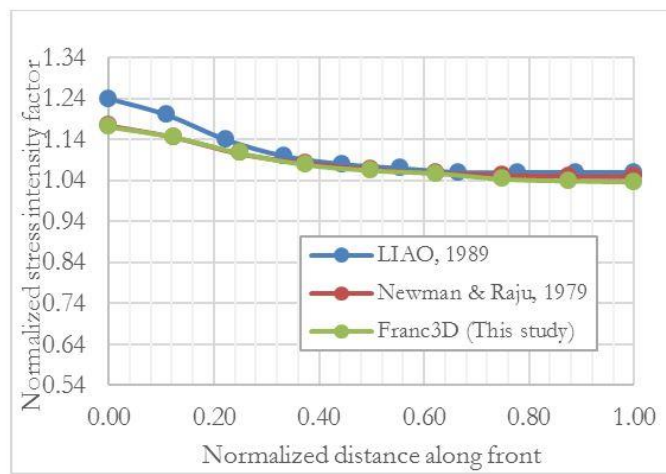

(a)

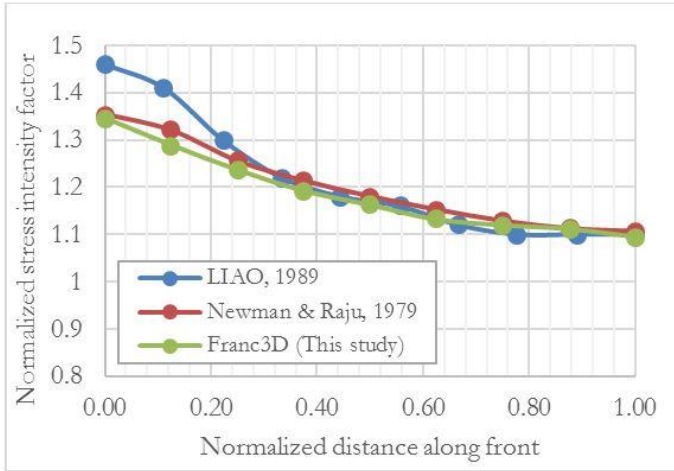

(c)

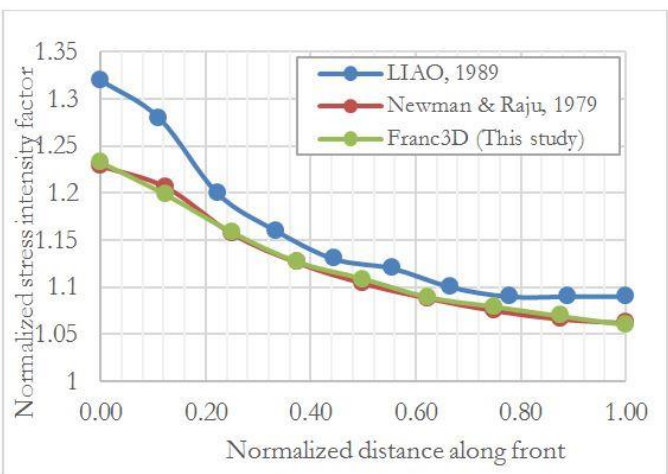

(b)

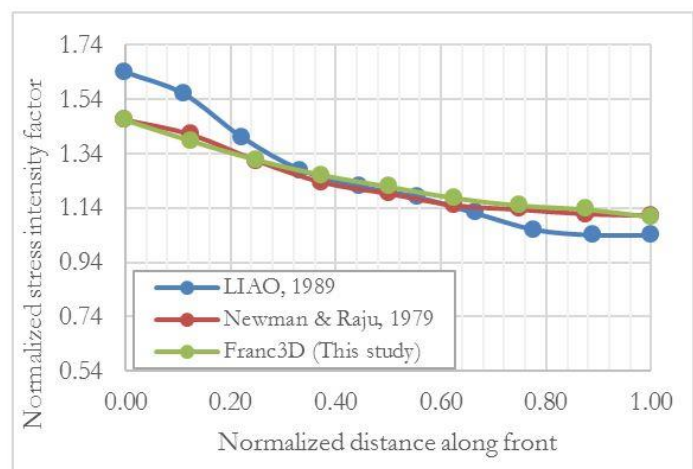

(d)

Fig. 6. Stress intensity factors along crack front under tension (a) $\mathrm{a} / \mathrm{t}=0.2$, (b) $\mathrm{a} / \mathrm{t}=0.4$, (c) $\mathrm{a} / \mathrm{t}=0.6$, and (d) $\mathrm{a} / \mathrm{t}=0.8$.

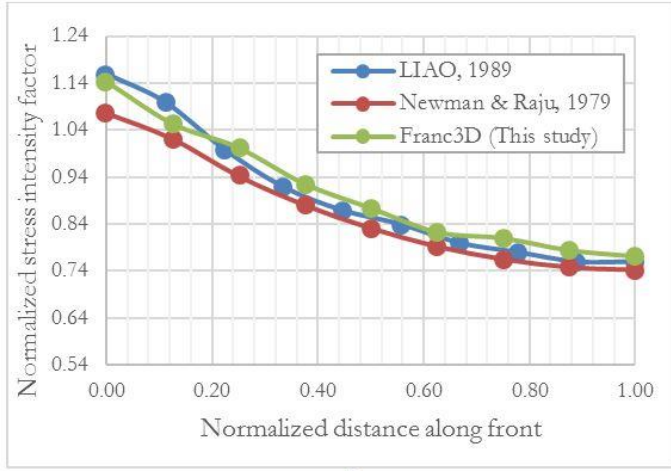

(a)

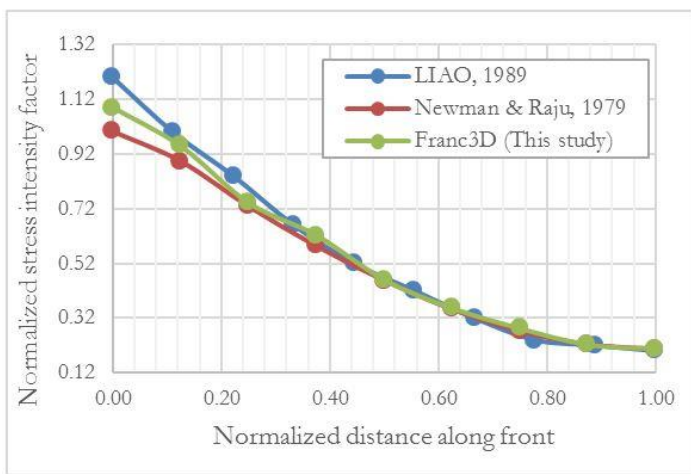

(c)

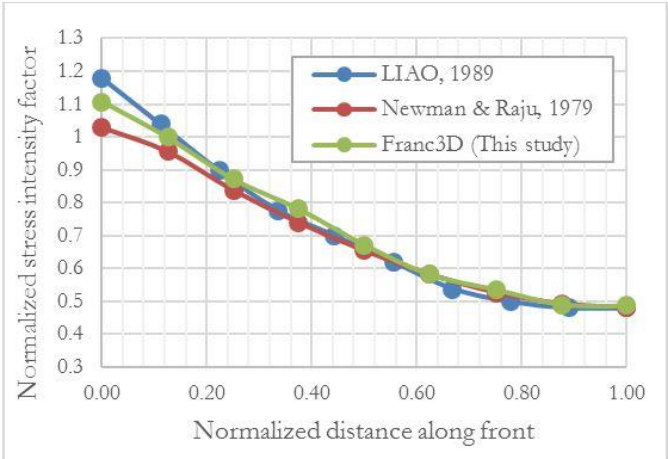

(b)

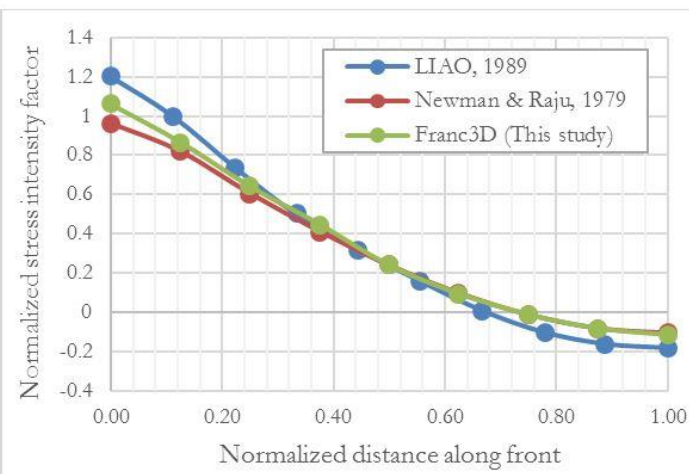

(d)

Fig. 7. Stress intensity factors along crack front under bending (a) $\mathrm{a} / \mathrm{t}=0.2$, (b) $\mathrm{a} / \mathrm{t}=0.4$, (c) $\mathrm{a} / \mathrm{t}=0.6$, and (d) $\mathrm{a} / \mathrm{t}=0.8$. 


\subsection{A Two-Tip Through-Thickness Web Crack in I-Beam under Bending}

Figure 8 shows a two-tip though-thickness web crack in a structural steel I-beam in a study by Albrecht et al. [14]. In this study, the W40 $\times 149$ steel beam (length $=6 \mathrm{~m}$, width $=300 \mathrm{~mm}$, depth $=949.2 \mathrm{~mm}$, flange thickness $=21.1 \mathrm{~mm}$, and web thickness $=16 \mathrm{~mm}$ ) was chosen. The crack eccentricity (e) and half crack length $\left(a_{\mathrm{w}}\right)$ of a two-tip through-thickness web crack were assumed to be 250 and $44.92 \mathrm{~mm}$, respectively. The stress intensity factors and fatigue life of the cracked steel beam under bending obtained from the FRANC3D were compared with the finite element analysis results.

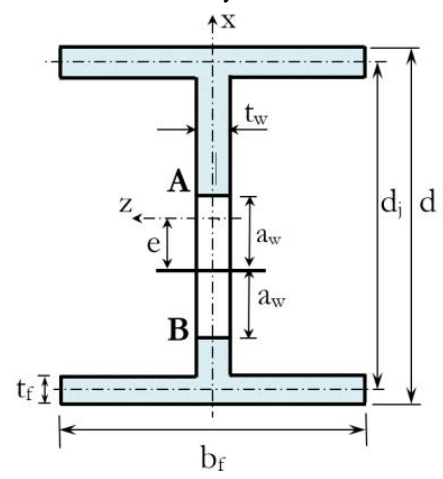

Fig. 8. A two-tip web crack in I-beam (adapted from [14]).

In Albrecht et al. [14], the stress intensity factor is given

$$
\Delta K=f^{B}\left(\lambda_{w}, \varepsilon, \beta\right) \Delta \sigma \sqrt{\pi a}
$$

where $f^{B}\left(\lambda_{w}, \varepsilon, \beta\right)$ is the correction factor for the lower crack tip of a two-tip web crack in the I-beam under bending and $\Delta \sigma$ is the bending stress at the flange-to-web junction.

The fatigue life was calculated using the Paris law [17] as follows:

$$
N=\int_{a_{0}}^{a_{f}} \frac{d a}{C(\Delta K)^{n}} \approx \sum_{a_{0}}^{a_{f}} \frac{\Delta a}{C(\Delta K)^{n}}
$$

where $N$ is the number of cycles. Two material constants $C$ and $n$ in the Paris law were assumed to be $5 \times$ $10^{8}$ and 1.5, respectively. A trapezoidal rule was used as the numerical integration scheme in Eq. (4).

Table 1 compares the stress intensity factors obtained from FRANC3D with those from Eq. (3). The relative differences were less than 6 percent. For the fatigue life, the maximum difference between the number of cycles obtained from FRANC3D and those from Eq. (4) was approximately 12 percent. 
Table 1. Stress intensity factor and fatigue life from FRANC3D and Albrecht et al. [14].

\begin{tabular}{|c|c|c|c|c|c|c|}
\hline \multirow{2}{*}{$\begin{array}{c}\text { Crack } \\
\text { length } \\
(\mathrm{mm})\end{array}$} & \multicolumn{2}{|c|}{ Stress intensity factor, $\mathrm{K}_{\mathrm{I}}\left(\mathrm{MPa} \mathrm{mm}^{0.5}\right)$} & \multicolumn{3}{|c|}{ Fatigue life, $\mathrm{N}_{\mathrm{f}}$ (cycles) } \\
\cline { 2 - 7 } & Eq. (3) & FRANC3D & $\begin{array}{c}\text { Relative } \\
\text { difference (\%) }\end{array}$ & Eq. (4) & FRANC3D & $\begin{array}{c}\text { Relative } \\
\text { difference (\%) }\end{array}$ \\
\hline 44.9 & 3,758 & 3,900 & 3.8 & - & - & - \\
\hline 50 & 4,006 & 4,150 & 3.6 & 492 & 500 & 1.6 \\
\hline 55 & 4,243 & 4,400 & 3.7 & 935 & 950 & 1.6 \\
\hline 60 & 4,474 & 4,600 & 2.8 & 1,342 & 1,400 & 4.3 \\
\hline 65 & 4,700 & 4,850 & 3.2 & 1,719 & 1,800 & 4.7 \\
\hline 70 & 4,922 & 5,150 & 4.6 & 2,090 & 2,200 & 5.3 \\
\hline 75 & 5,140 & 5,400 & 5.1 & 2,398 & 2,500 & 4.3 \\
\hline 80 & 5,354 & 5,600 & 4.6 & 2,707 & 2,850 & 5.3 \\
\hline 85 & 5,565 & 5,800 & 4.2 & 2,997 & 3,200 & 6.8 \\
\hline 90 & 5,774 & 6,000 & 3.9 & 3,271 & 3,550 & 8.5 \\
\hline 95 & 5,979 & 6,300 & 5.4 & 3,532 & 3,900 & 10.4 \\
\hline 100 & 6,182 & 6,500 & 5.1 & 3,779 & 4,200 & 11.1 \\
\hline 105 & 6,382 & 6,750 & 5.8 & 4,014 & 4,500 & 12.1 \\
\hline
\end{tabular}

\subsection{A Crack in a Fillet under Mixed-Mode Condition}

Figure 9 shows a crack at a fillet of a structural member under a mixed-mode condition in a study by Bouchard et al [15]. The member is supported at bottom by an I-beam. The predicted propagation of a crack from the fillet weld toe that joins the bottom flange and web plate was compared with experimental results by Sumi et al. [18]. Two sizes of the bottom I-beam of 15 and $315 \mathrm{~mm}$ were used to investigate the effect of bending stiffness on the mixed-mode crack propagation path. A plane strain condition was assumed. The Poisson's ratio and elastic modulus of the material were 0.3 and $200 \mathrm{GPa}$, respectively. Residual stresses were neglected in the analysis. The initial crack size was $5 \mathrm{~mm}$.

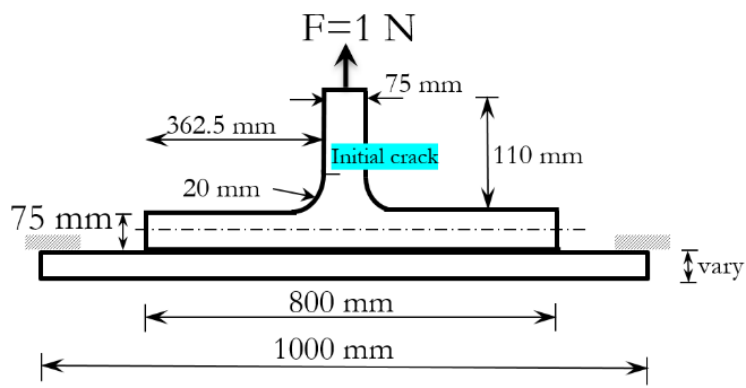

Fig. 9. An initial crack beside the fillet weld toe (adapted from [15]).

Figures 10 and 11 show the crack propagation paths from the FRANC3D in cases of flexible and rigid support, respectively. In case of a flexible support, the crack propagates down considerably to the bottom flange. In case of a rigid support, on the other hand, the crack propagation remains horizontal while the path passes through the web plate before the other side of the web is reached. The FRANC3D results are similar to those from the previous studies $[15,18]$. 

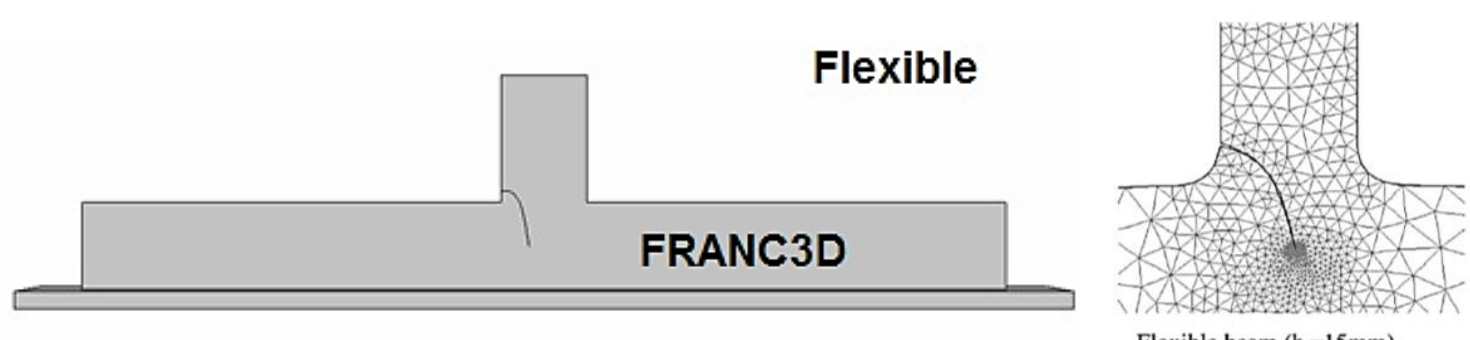

Flexible beam $\left(\mathrm{h}_{\mathrm{l}}=15 \mathrm{~mm}\right)$

Fig. 10. Fatigue crack propagation path in case of flexible support (a) FRANC3D (b) Bouchard et al [15].

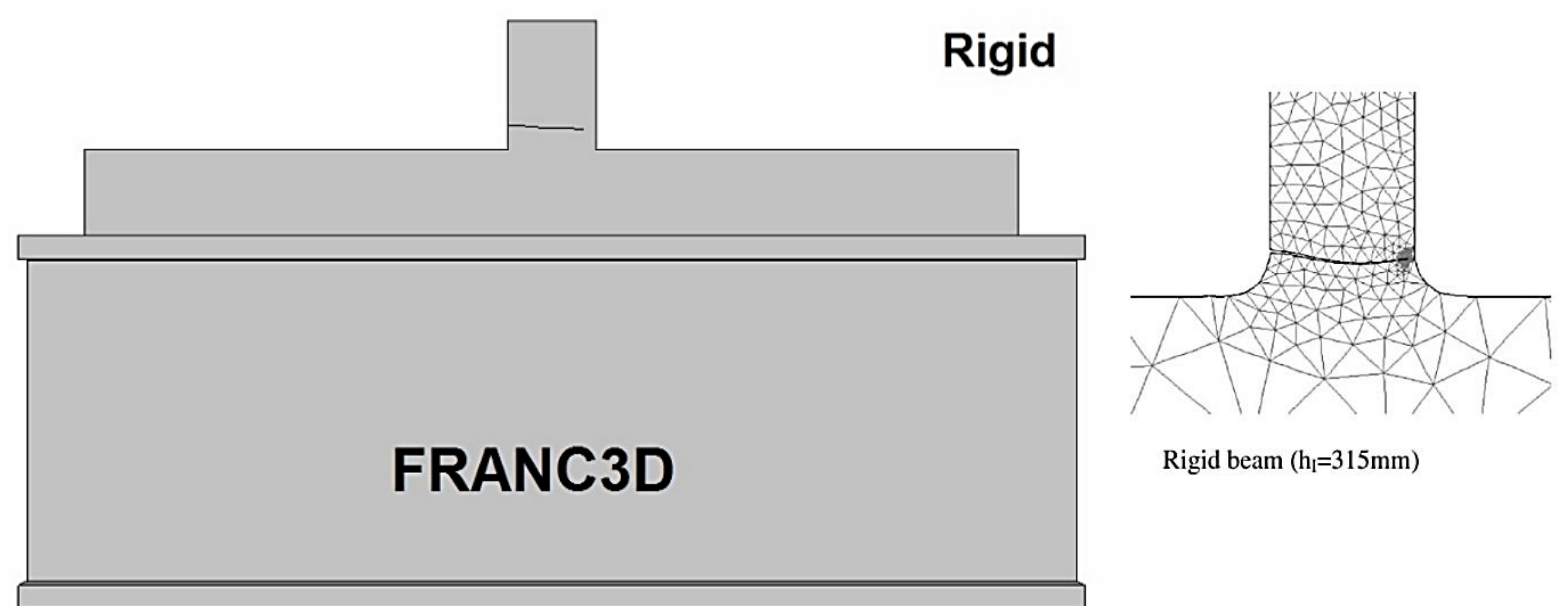

Fig. 11. Fatigue crack propagation path in case of rigid support (a) FRANC3D (b) Bouchard et al [15].

\section{Finite Element Analysis for Steel I-Beams with Welded Transverse Stiffeners Subjected to In-Plane Loadings}

Figures 12 and 13 show the details and finite element model of a simply-supported steel I-beam under fourpoint bending, respectively. The span length of the beam was $6 \mathrm{~m}$. The beam width and depth were 300 and $930 \mathrm{~mm}$, respectively. The flange and web thicknesses were 20 and $16 \mathrm{~mm}$, respectively. The transverse stiffeners of $100-\mathrm{mm}$ wide and $12-\mathrm{mm}$ thick were welded to both sides of the web. The web gap was 90 $\mathrm{mm}$. The transverse stiffeners were designed to have sufficient rigidity according to AASHTO [3]. The steel grade was ASTM A36 with elastic modulus, Poisson's ratio, and fracture toughness of $200 \mathrm{GPa}, 0.29$, and $90 \mathrm{ksi} \sqrt{(i n .)}$ (or 3,165 $\mathrm{MPa} \sqrt{ }(\mathrm{mm})$ ), respectively [19]. A constant amplitude cyclic loading with a stress ratio of 0.1 was assumed. The residual stresses were neglected in the analysis. The steel beams were modelled as a combination of top flange, bottom flange, web, and transverse stiffener plates. Fillet welds were not included in the model. An eight-node solid element - ANSYS designation of brick 8 node 185 - was used. The element was defined by eight nodes. Each node had three degrees of freedom: translations in the nodal $\mathrm{x}, \mathrm{y}$, and $\mathrm{z}$ directions. Approximately 105,000 elements were used for the entire model. A simple support condition was assumed by constraining the vertical displacement $\left(\mathrm{u}_{\mathrm{y}}\right)$ along the bottom line at the left end and all displacements $\left(\mathrm{u}_{\mathrm{x}}, \mathrm{u}_{\mathrm{y}}, \mathrm{u}_{\mathrm{z}}\right)$ along the bottom line at the right end. 


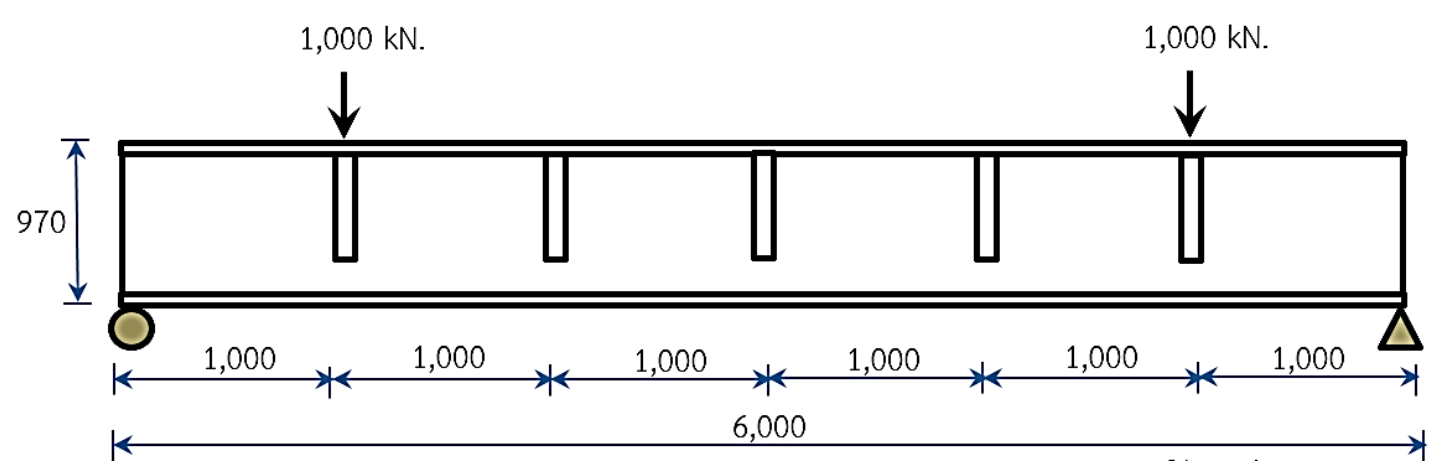

Fig. 12. Details of steel I-beam under four-point bending (dimensions in $\mathrm{mm}$ ).

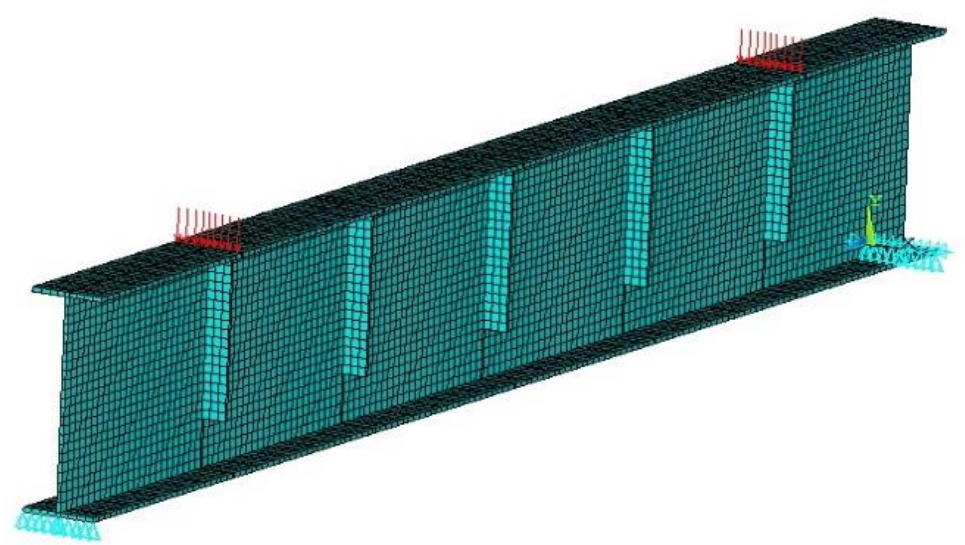

Fig. 13. A finite element model of steel I-beam with welded transverse stiffeners.

Figure 14 shows the two phases of fatigue crack propagation in this study. In Phase I, the fatigue crack was assumed to initiate on the web surface at the weld toe at bottom end of the transverse stiffener. The assumed shape of the initial crack was semi-circular. In Phase II, the two-tip though-thickness web crack propagates up and down the web. The initial crack configurations for phase I and II in the FRANC3D are shown in Fig. 15.

Figure 16 shows the cross section of steel I-beam. As the point B was the critical point on the crack front with the highest values of the stress intensity factor, the crack length was defined as the vertical distance "a" measured from the end of the transverse stiffener to the point B. In this study, initial crack sizes in Phase I $\left(a_{0}^{I}\right)$ and Phase II $\left(a_{0}^{I I}\right)$ were 1 and $16 \mathrm{~mm}$.

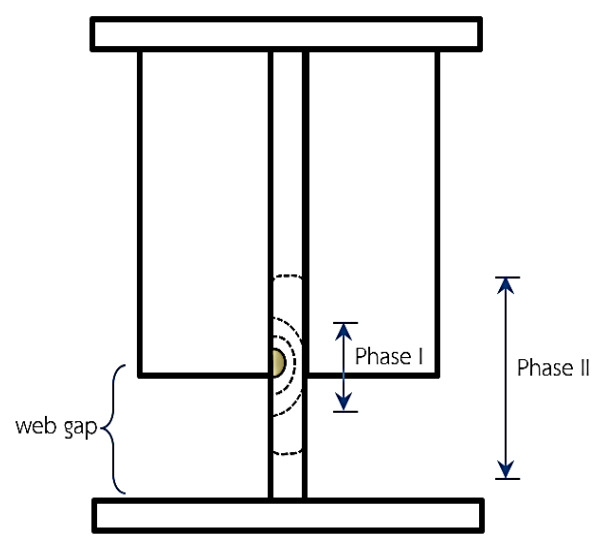

Fig. 14. Two phases of crack propagation in steel I-beams with welded transverse stiffeners. 


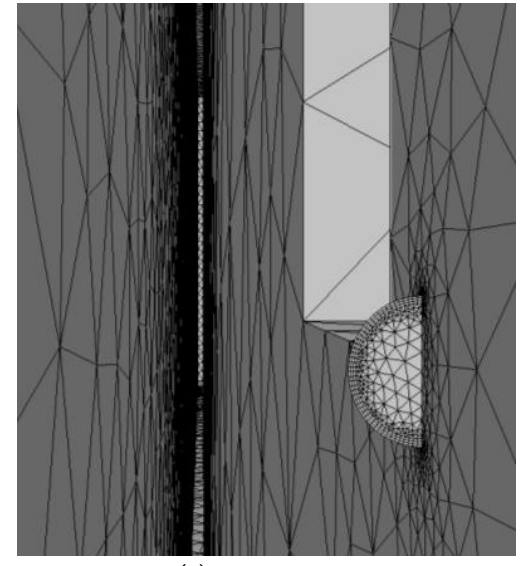

(a)

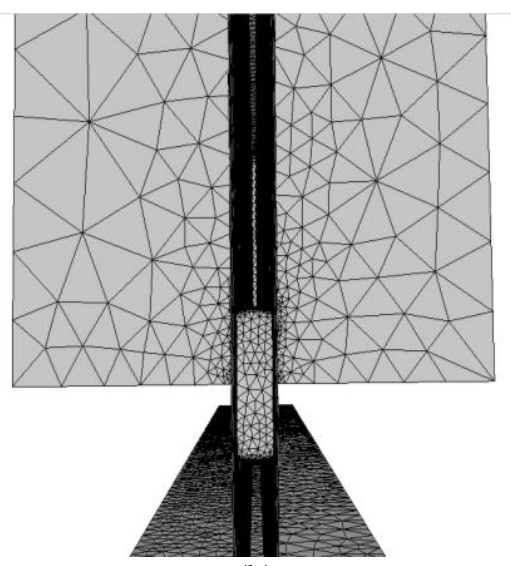

(b)

Fig. 15. Initial crack configurations in FRANC3D (a) Phase I (b) Phase II.

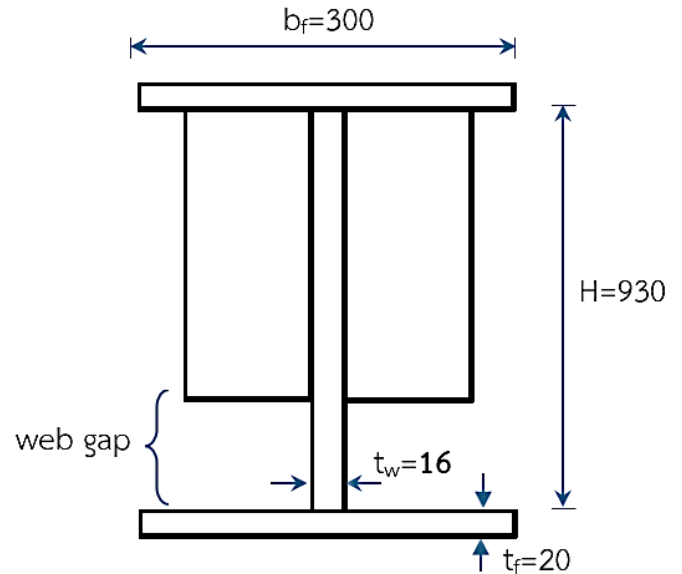

Fig. 16. Cross section of steel I-beam (a) semi-circular crack and (b) two-tip through-thickness crack (dimensions in $\mathrm{mm}$ ).

In FRANC3D, the M-integral was used to calculate stress intensity factor from stress and displacement fields near the crack tip [20]. Two material constants $C$ and $n$ in the Paris law were assumed to be $5 \times 10^{8}$ and 1.5, respectively. The crack growth increment was chosen to be less than twenty times of the total fatigue life.

\section{Effects of Parameters on Fatigue Crack Propagation}

\subsection{Initial Crack Size}

Figure 17 shows the initial semi-circular crack in Phase I in FRANC3D. In practice, an initial crack size of $0.25 \mathrm{~mm}$ (0.01 in) can be assumed [21]. In this study, the values of $a_{0}^{I}$ were varied to be $1,2,4,8$, and 12 $\mathrm{mm}$. In Phase II, the value of $a_{0}^{I I}$ for the two-tip through-thickness shape was $16 \mathrm{~mm}$ which is the web thickness. Figure 18 shows the transitional stage when the fatigue crack in Phase I propagates until it reaches the other side of the web, i.e., it penetrates through the web plate, and becomes the fatigue crack in Phase II. 

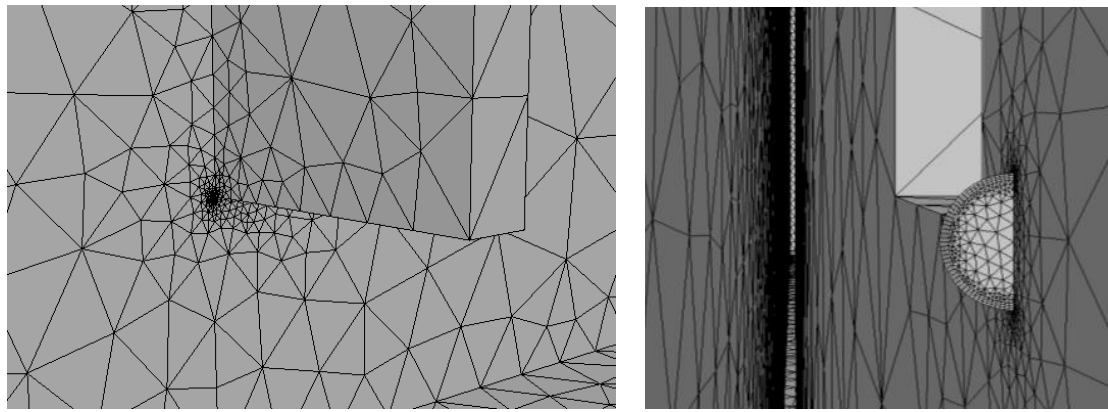

Fig. 17. Initial crack configuration in Phase I.

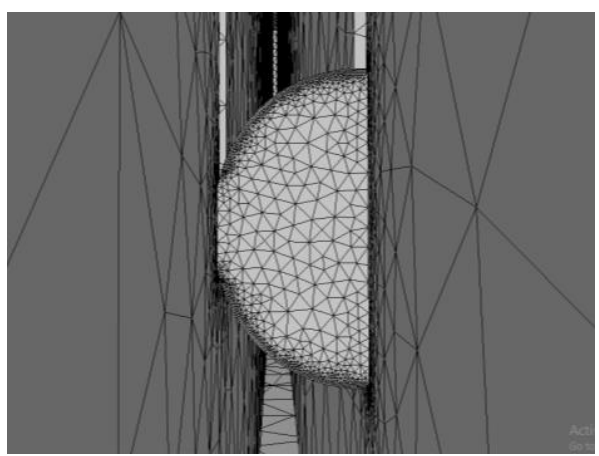

Fig. 18. Transition of fatigue crack propagation from phase I to phase II.

Figure 19 plots the calculated stress intensity factors at point B (lower crack tip) of the web crack in the steel I-beam (web-gap length of $90 \mathrm{~mm}$ ) as a function of crack length "a". The vertical line at a $=16 \mathrm{~mm}$ separates the crack propagation in Phase I and Phase II. The critical or final crack size $\left(a_{f}\right)$ calculated from the fracture toughness was $18 \mathrm{~mm}$. Discontinuities in the stress intensity factor values at the transition stage was observed when the fatigue crack shape changes. In case of $a_{0}^{I}=1 \mathrm{~mm}$, the FRANC3D predicted approximately 8,500 and 800 cycles in Phase I and II, respectively. Figure 20 plots the relationship between the crack size and number of load cycles.

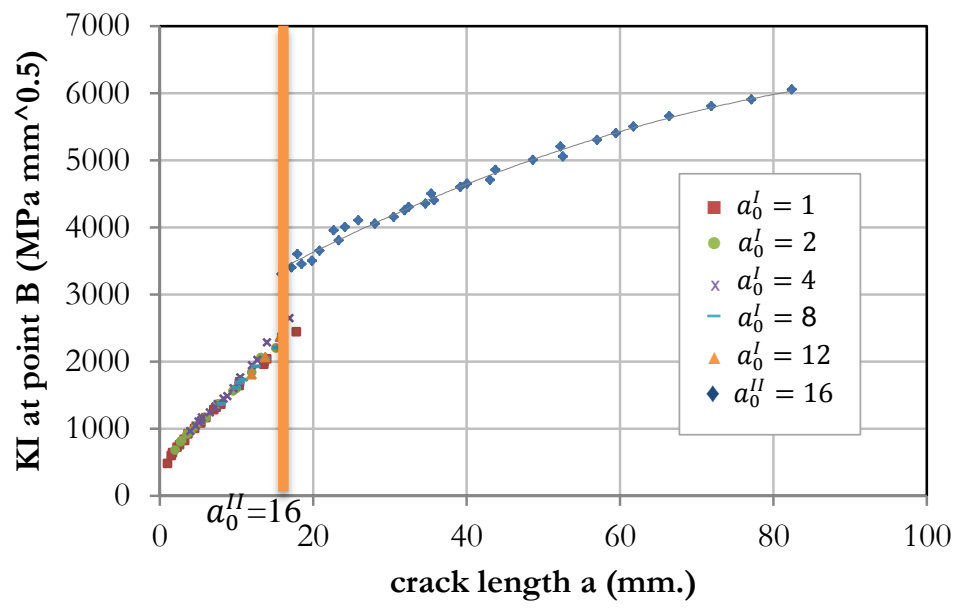

Fig. 19. Calculated stress intensity factor vs. crack size. 


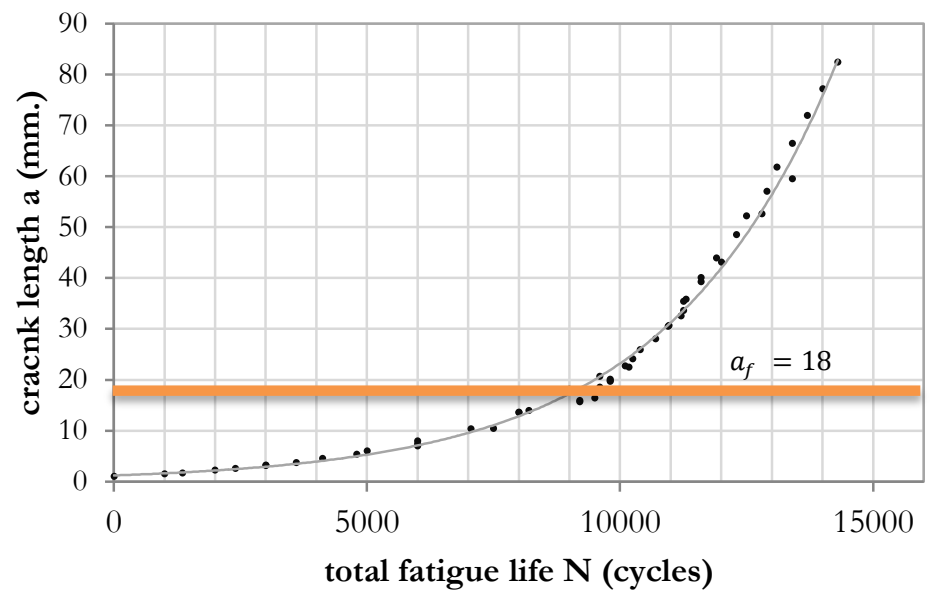

Fig. 20. Calculated crack length v.s. number of cycles (web-gap length is $90 \mathrm{~mm}$ ).

Table 2 shows the effect of initial crack sizes on calculated fatigue life. The number of cycles in phase I, phase II, and the total number $\left(\mathrm{N}_{\mathrm{I}}+\mathrm{N}_{\mathrm{II}}\right)$ were represented by $\mathrm{N}_{\mathrm{I}}, \mathrm{N}_{\mathrm{II}}$, and $\mathrm{N}$, respectively. During an initial phase of crack propagation (Phase I), a high number of cycles is usually required. The fatigue life ratio $\mathrm{N}_{\mathrm{I}} / \mathrm{N}$ decreased as the initial crack size increased. Therefore, the initial cracks or weld defects should be minimized to increase the service life of the steel beams.

Table 2. Effect of initial crack sizes on calculated fatigue life.

\begin{tabular}{|c|c|c|c|c|c|}
\hline \multicolumn{2}{|c|}{ Phase I (semi-circular crack) } & \multicolumn{3}{|c|}{ Phase II (two-tip web crack) } & Fatigue \\
\hline $\begin{array}{c}\text { Initial crack } \\
\left(a_{0}^{I}\right)(\mathrm{mm} .)\end{array}$ & $\mathrm{N}_{\mathrm{I}}$ (cycles) & $\begin{array}{c}\text { Initial crack } \\
\left(a_{0}^{I I}\right)(\mathrm{mm})\end{array}$ & $\begin{array}{c}\text { Final } \\
\text { crack, } \mathrm{a}_{\mathrm{f}} \\
(\mathrm{mm})\end{array}$ & $\mathrm{N}_{\mathrm{II}}$ (cycles) & $\begin{array}{c}\text { ratio } \\
\left(\mathrm{N}_{\mathrm{I}} / \mathrm{N}\right)\end{array}$ \\
\hline 1 & 8,500 & 16 & 18 & 800 & 0.91 \\
\hline 2 & 6,700 & 16 & 18 & 800 & 0.89 \\
\hline 4 & 4,800 & 16 & 18 & 800 & 0.86 \\
\hline 8 & 2,400 & 16 & 18 & 800 & 0.75 \\
\hline 12 & 1,000 & 16 & 18 & 800 & 0.56 \\
\hline
\end{tabular}

\subsection{Web-Gap Length}

The AASHTO [3] recommended the web-gap length of four to six times the web thickness. In this study the web-gap lengths were varied to be 90, 215, and $340 \mathrm{~mm}$ as shown in Fig. 21. 


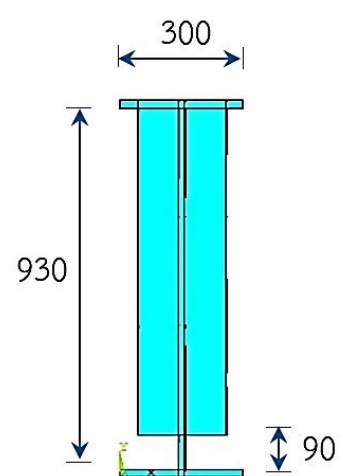

(a)

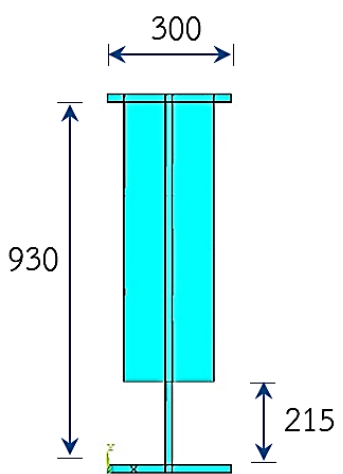

(b)

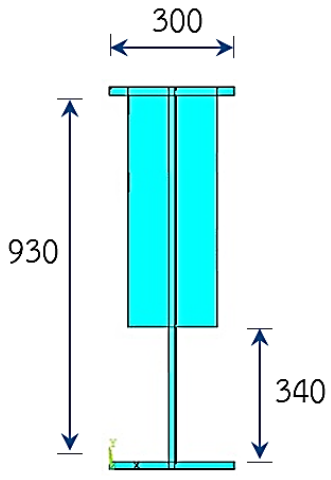

(c)

Fig. 21. Cross section of steel I-beams with different web gap lengths (a) $90 \mathrm{~mm}$ (b) $215 \mathrm{~mm}$ (c) $340 \mathrm{~mm}$.

Table 3 shows the effect of web-gap length on calculated fatigue life. The web-gap length was also represented by the ratio of gap length to half of the web height $(\mathrm{H} / 2=465 \mathrm{~mm})$. The calculated fatigue life for the web-gap lengths of 90, 215, and $340 \mathrm{~mm}$ were 9300, 20900, and 65000 cycles, respectively. It can be seen that the fatigue life in both phases increased as the web gap length increased. Also, the fatigue life ratio $\mathrm{N}_{\mathrm{I}} / \mathrm{N}$ decreased as the web gap length increased because the fatigue crack propagation in Phase II governed the fatigue life. A small web-gap length produces a high stress intensity factor which shortens the fatigue life. The effect of web-gap length was nonlinear as shown in Fig. 22.

Table 3. Effect of web-gap length on calculated fatigue life.

\begin{tabular}{|c|c|c|c|c|c|c|}
\hline \multirow{2}{*}{$\begin{array}{c}\text { Web-gap } \\
\text { length } \\
\text { (mm.) }\end{array}$} & $\begin{array}{c}\text { web-gap } \\
\text { length } \\
\text { (gap/half of } \\
\text { web height) }\end{array}$ & $\begin{array}{c}\text { Final } \\
\text { crack, af } \\
(\mathrm{mm})\end{array}$ & \multicolumn{4}{|c|}{ Fatigue life (cycles) } \\
\cline { 5 - 7 } & & $\mathrm{N}_{\mathrm{I}}$ & $\mathrm{N}_{\mathrm{II}}$ & $\begin{array}{c}\mathrm{N}_{\mathrm{I}}+\mathrm{N}_{\mathrm{II}} \\
=\mathrm{N}\end{array}$ & $\mathrm{N}_{\mathrm{I}} / \mathrm{N}$ \\
\hline 90 & 0.19 & 18 & 8,500 & 800 & 9,300 & 0.91 \\
\hline 215 & 0.46 & 42 & 16,200 & 4,700 & 20,900 & 0.78 \\
\hline 340 & 0.73 & 101 & 33,000 & 32,000 & 65,000 & 0.51 \\
\hline
\end{tabular}

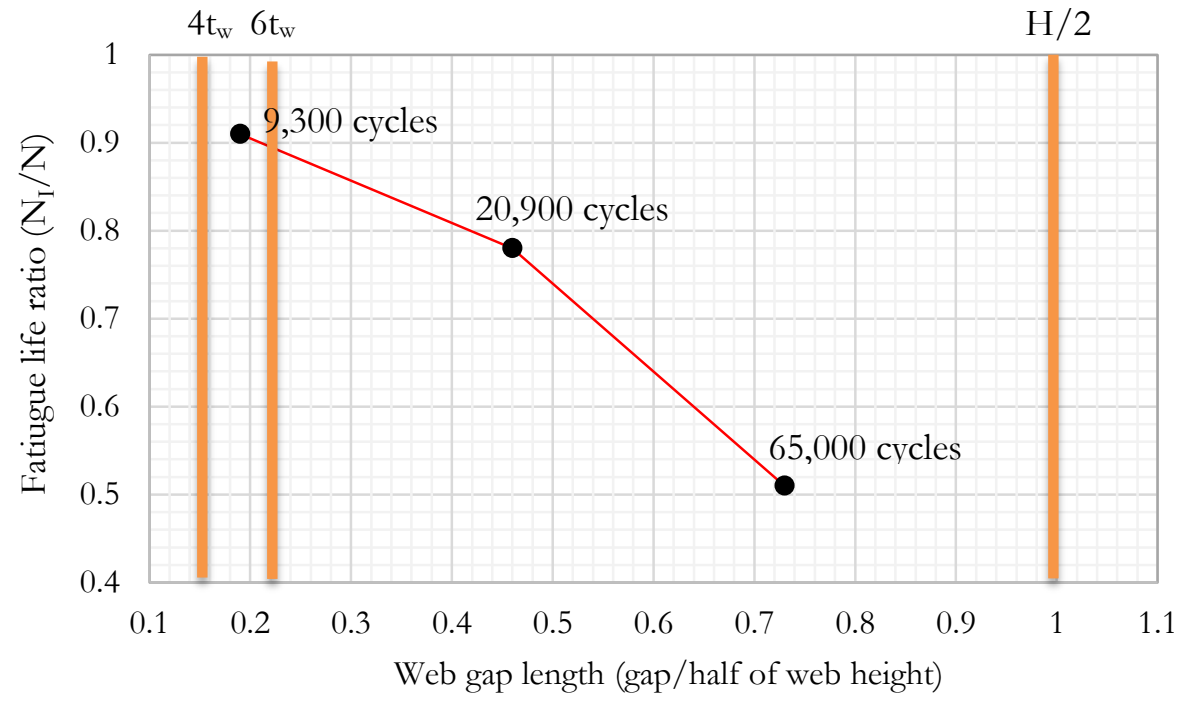

Fig. 22. Effect of web-gap length on fatigue life. 


\subsection{Transverse Stiffener Dimension}

The transverse stiffeners must have sufficient rigidity to develop the shear-bucking resistance or combined shear-buckling and postbuckling tension-field resistance of the steel beam [2]. In this study, the flexural rigidity ratio (EI) is defined as the ratio of flexural rigidity $(\mathrm{EI})_{\text {st }}$ of the transverse stiffener about the z-axis in Eq. (5) to the flexural rigidity (EI) girder of the girder about $\mathrm{x}$-axis in Eq. (6). Figure 23 shows the axis and directions of the moment of inertia of double-sided transverse stiffeners in this study.

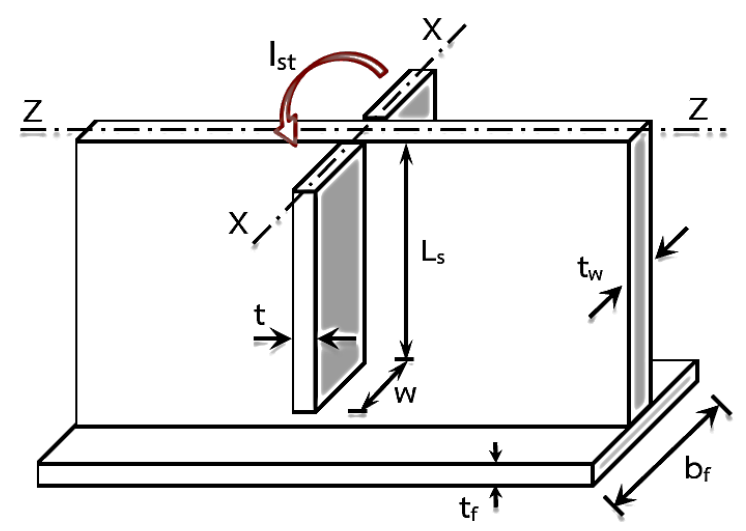

Fig. 23. A moment of inertia of double-sided transverse stiffeners.

and

$$
E I_{s t}=E\left[\frac{1}{12} t\left[\left(2 w+t_{w}\right)^{3}-t_{w}^{3}\right]\right]
$$

$$
E I_{\text {girder }}=E\left[\frac{1}{12} t_{w} H^{3}+2\left[\frac{1}{12} b_{f} t_{f}^{3}+\left(b_{f} t_{f}\right)\left(\frac{H+t_{f}}{2}\right)^{2}\right]\right]
$$

then

$$
\text { Flexural rigidity ratio }=(E I)_{s t} /(E I)_{\text {girder }}
$$

Figure 24 shows the cross section of steel I-beams with different flexural rigidity ratios. The flexural rigidity ratios were varied to be $2.66 \times 10^{-3}, 4.44 \times 10^{-3}, 5.92 \times 10^{-3}$, and $7.39 \times 10^{-3}$, respectively.

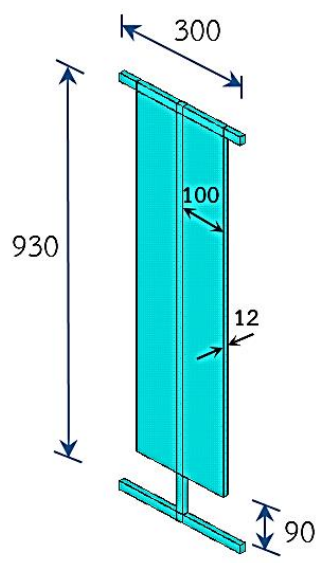

(a)

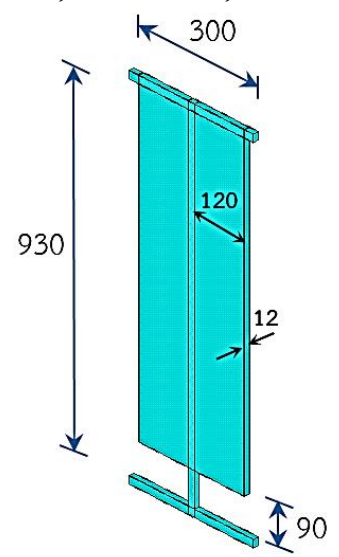

(b)

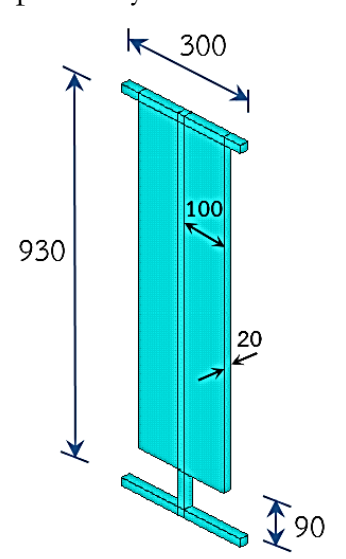

(c) 


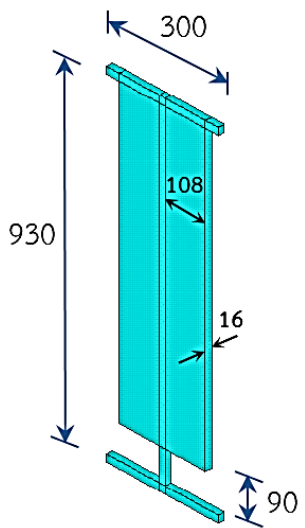

(d)

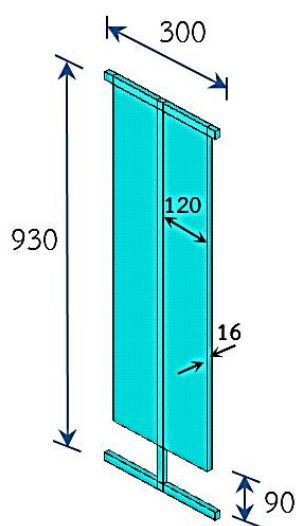

(e)

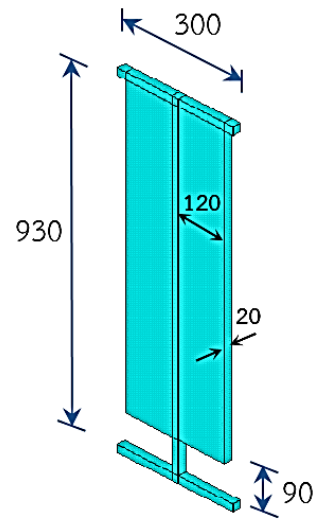

(f)

Fig. 24. Cross section of steel I-beams with different flexural rigidity ratios (a) $2.66 \times 10^{-3}$, (b), (c), (d) $4.44 \times$ $10^{-3}$ (e) $5.92 \times 10^{-3}$ and (f) $7.39 \times 10^{-3}$.

Table 4 shows the effect of stiffener dimension on the fatigue life. No correlation between the flexural rigidity ratios and fatigue life of steel I-beams with welded transverse stiffeners was found. However, the stress intensity factor increased as the thickness of transverse stiffeners increased. Therefore, the fatigue life decreased as the thickness of stiffener increased as shown in Fig. 25.

Table 4. Effect of stiffener dimension on calculated fatigue life.

\begin{tabular}{|c|c|c|c|c|c|c|c|}
\hline \multirow{2}{*}{$\begin{array}{l}\text { Flexural } \\
\text { rigidity } \\
\text { ratio }\end{array}$} & \multicolumn{2}{|c|}{$\begin{array}{c}\text { Stiffener } \\
\text { dimension }(\mathrm{mm})\end{array}$} & \multirow{2}{*}{$\begin{array}{c}\text { Final } \\
\text { crack, } \\
a_{\mathrm{f}} \\
(\mathrm{mm})\end{array}$} & \multicolumn{4}{|c|}{ Fatigue life (cycles) } \\
\hline & Thickness & Width & & $\mathrm{N}_{\mathrm{I}}$ & $\mathrm{N}_{\text {II }}$ & $\mathrm{N}_{\mathrm{I}}+\mathrm{N}_{\mathrm{II}}=\mathrm{N}$ & $\mathrm{N}_{\mathrm{I}} / \mathrm{N}$ \\
\hline $2.66 \times 10^{-3}$ & 12 & 100 & 18 & 8,500 & 800 & 9,300 & 0.91 \\
\hline $4.44 \times 10^{-3}$ & 12 & 120 & 17 & 8,800 & 300 & 9,100 & 0.97 \\
\hline $4.44 \times 10^{-3}$ & 16 & 108 & 16 & 5,700 & - & 5,700 & 1.0 \\
\hline $5.92 \times 10^{-3}$ & 16 & 120 & 16 & 5,900 & - & 5,900 & 1.0 \\
\hline $4.44 \times 10^{-3}$ & 20 & 100 & 12 & 3,500 & - & 3,500 & 1.0 \\
\hline $7.39 \times 10^{-3}$ & 20 & 120 & 13 & 3,400 & - & 3,400 & 1.0 \\
\hline
\end{tabular}

$\mathscr{W} 2.66 \times 10^{-3} \square .44 \times 10^{-3} \quad{ }^{-3} .92 \times 10^{-3}$ 田 $7.39 \times 10^{-3}$

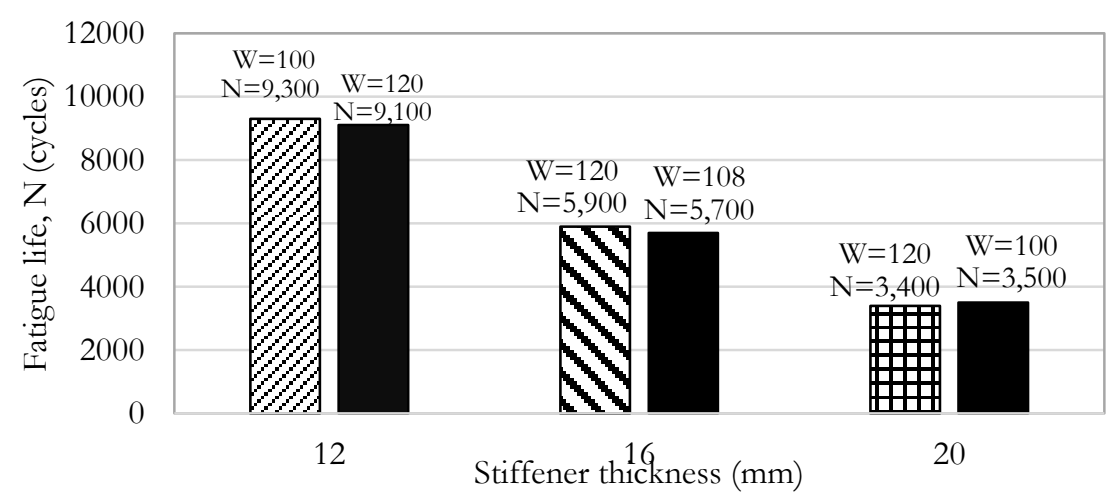

Fig. 25. Effect of stiffener thickness on fatigue life. 


\subsection{Fillet Weld Size}

To investigate the effect of the fillet weld on the stress intensity factor, the finite element models that include the fillet weld were also analyzed. Figure 26 shows the modelling of a fillet weld that connects the transverse stiffener to the beam web. Two fillet weld sizes of 2 and $5 \mathrm{~mm}$ were chosen.

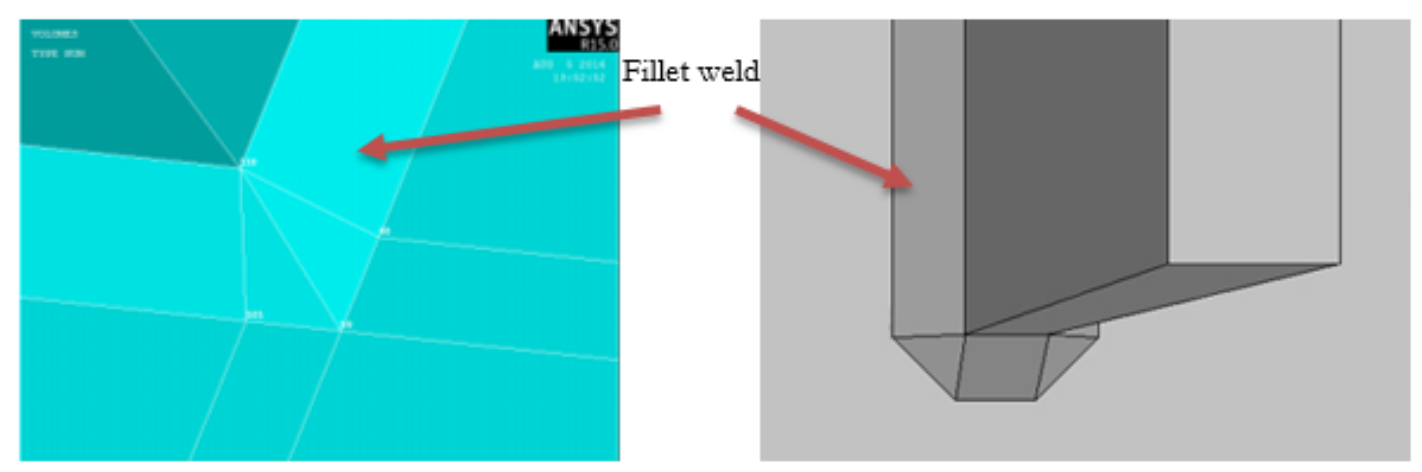

Fig. 26. Fillet weld that connects transverse stiffener to web of steel beam.

Figures 27 and 28 show the stress intensity factors for fillet weld sizes of 2 and $5 \mathrm{~mm}$, respectively. The calculated stress intensity factors without fillet welds are also compared. An initial crack located away from the web plate 2 and $5 \mathrm{~mm}$, respectively. Both figures show that the stress intensity factors of the steel Ibeam with fillet weld are slightly lower than ones without fillet weld. A more gradual change in geometry due to the fillet weld resulted in a lower stress concentration. In the studied problem, the effect of fillet weld size on the stress intensity factor and fatigue life was not significant.

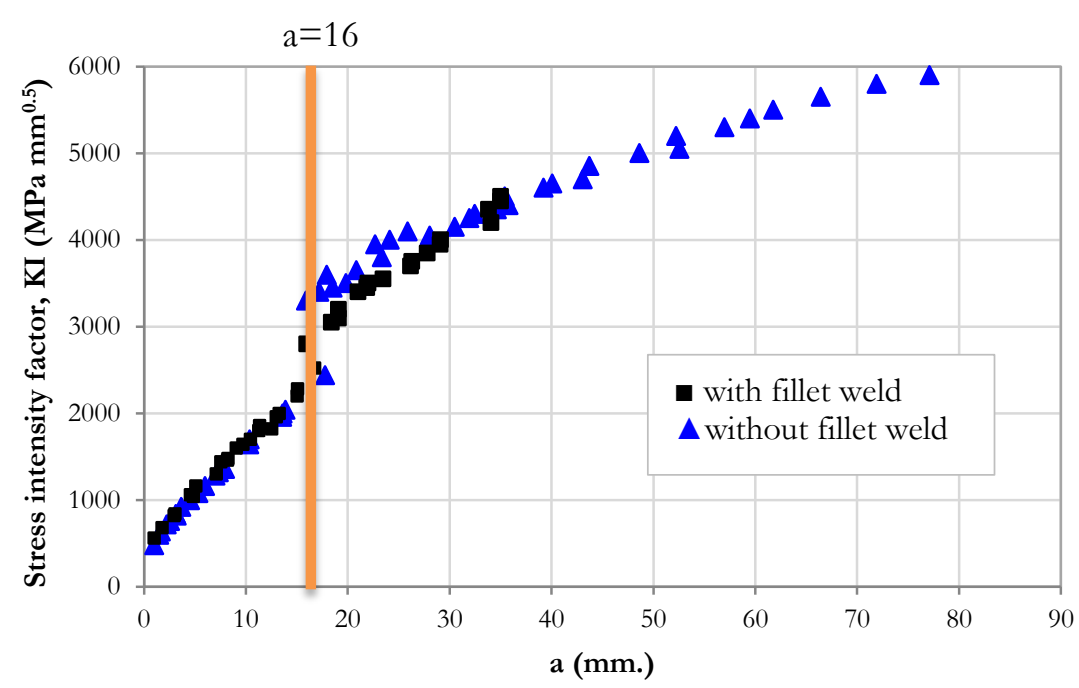

Fig. 27. Calculated SIFs for steel I-beams with fillet weld size of $2 \mathrm{~mm}$. 


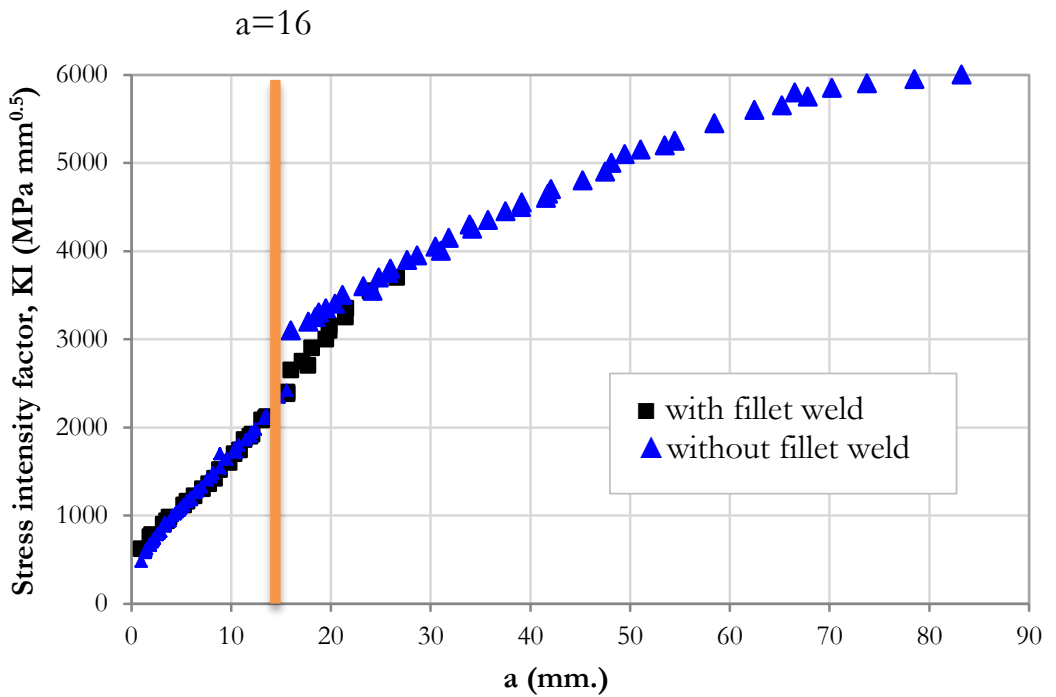

Fig. 28. Calculated SIFs for steel I-beams with fillet weld size of $5 \mathrm{~mm}$.

\section{Conclusions}

A long life fatigue crack propagation simulation on steel I-beams with welded transverse stiffeners under constant amplitude in-plane loading was carried out by the FRANC3D. The effects of initial crack size, web-gap length, transverse stiffener dimension, and fillet weld size on the fatigue crack propagation were studied. The main findings can be summarized as follows:

1. During an initial phase of crack propagation (Phase I), a high number of cycles is required. Therefore, the initial cracks or weld defects should be minimized to increase the service life of the steel beams.

2. A small web-gap length produces a high stress intensity factor which shortens the fatigue life.

3. Dimensions of the transverse stiffener influence the fatigue life of steel I-beams. The fatigue life decreases as the stiffener thickness increases.

4. The stress intensity factors of the steel I-beams that include the fillet weld in the finite element models are slightly lower than ones modelled without fillet weld.

\section{Acknowledgement}

The scholarship from the Graduate School, Chulalongkorn University to commemorate the $72^{\text {nd }}$ anniversary of his Majesty King Bhumibol Aduladej is gratefully acknowledged.

\section{References}

[1] J. S. Huang and B. T. Yen, "Stiffener requirements for plate girders, June 1968," Fritz Laboratory Reports, Paper 1918. Available: http://preserve.lehigh.edu/engr-civil-environmental-fritz-labreports/1918 [Accessed: 16 January 2017]

[2] J. W. Fisher, P. Albrecht, B. T. Yen, D. J. Klingerman, and B. M. McNamee, "Fatigue strength of steel beams with welded stiffeners and attachments," NCHRP Rep. No. 147, Transportation Research Board, Washington, D.C., 1974.

[3] AASHTO, LRFD Bridge Specifications. Washington, D.C., 2012.

[4] H. T. Dinh, "Analysis of distortion-induced fatigue crack at the web gap of I-beam in steel bridges," Ph.D. thesis, Department of Civil Engineering, Chulalongkorn University, Bangkok, Thailand, 2012.

[5] H. T. Dinh, A. Lenwari, T. Senjuntichai, and T. Hayashikawa, "Distortion-induced fatigue cracking at web-gap of welded I-beams," ASEAN Engineering Joumal (AEJ) Part C, vol. 3, no. 1, pp. 9-20, 2014.

[6] A. Boulenouar, N. Benseddiq, and M. Mazari, "Strain energy density prediction of crack propagation for 2D linear elastic materials," Theor Appl Fract Mec, vol. 67-68, pp. 29-37, 2013.

[7] M. Aygül, "Fatigue evaluation of welded details using the finite element method," Department of Civil and Environmental Engineering, Chalmers University of Technology, 2013. 
[8] A. Duchaczek and Z. Mańko, "The influence of a cracking mode on fatigue crack propagation in steel girders in military bridges," Eur J Environ Civ En, vol. 20, no. 1, pp. 1-18, 2016.

[9] G. Kotsikos and M. Grasso, "Assessment of fatigue cracks in rails," Procedia - Social and Behavioral Sciences, vol. 48, pp. 1395-1402, 2012.

[10] M. Aygül, M. Al-Emrani, Z. Barsoum, and J. Leander, "Investigation of distortion-induced fatigue cracked welded details using 3D crack propagation analysis," Int. J. Fatigue, vol. 64, pp. 54-66, 2014.

[11] L. Zong, G. Shi, and Y. Wang, "Experimental investigation and numerical simulation on fatigue crack behavior of bridge steel WNQ570 base metal and butt weld," Constr Build Mater, vol. 77, pp. 419-429, 2015.

[12] FRANC3D, Reference Manual version 6. Fracture Analysis Consultants Inc., 2011.

[13] J. C. Newman Jr and I. S. Raju, "Analyses of surface cracks in finite plates under tension or bending loads," NASA Technical Paper, 1979.

[14] P. Albrecht, A. Lenwari, and D. Feng, "Stress intensity factors for structural steel I-beams," J Struct Eng, ASCE, vol. 134, no. 3, pp. 421-429, 2008.

[15] P. O. Bouchard, F. Bay, and Y. Chastel, "Numerical modelling of crack propagation: Automatic remeshing and comparison of different criteria," Comput Methods Appl Mech Eng, vol. 192, pp. 38873908, 2003.

[16] C. Y. Liao and S. N. Atluri, "Stress intensity factor variation along a semicircular surface flaw in a finite-thickness plate," Eng Fract Mech, vol. 34, pp. 957-976, 1989.

[17] P. Paris and F. Erdogan, "A critical analysis of crack propagation laws," J Basic Eng, vol. 85, pp. 528533, 1963.

[18] Y. Sumi, C. Yang, and Z. N. Wang, "Morphological aspects of fatigue crack propagation Part IIEffects of stress biaxiality and welding residual stress," Int J Fracture, vol. 82, pp. 221-235, 1996.

[19] M. K. S. K. Nagoju and V. Gopinath, "Computation of stress intensity factor and critical crack length of ASTM A36 steel using fracture mechanics," International Journal of Engineering Research and Technology (IJERT), vol. 2, pp. 2677- 2683, 2013.

[20] R. Z. Liang, Z. C. Rui, Z. Y. Liang, and Z. H. Bo, "M-integral for stress intensity factor base on XFEM," in International Symposium on Electronic Commerce and Security Workshops, Guangzhou, P.R. China, 2010, pp. 226-230.

[21] FHWA, "Manual for repair and retrofit of fatigue cracks in steel bridges," FHWA Publication No. FHWA-IF-13-020, U.S. Department of Transportation, 2013. 